Sérgio R. A. Soares 1

\title{
Relações entre saneamento, saúde pública e meio ambiente: elementos para formulação de um modelo de planejamento em saneamento
}

\author{
Relationship between water supply, sanitation, \\ public health, and environment: elements \\ for the formulation of a sanitary infrastructure \\ planning model
}

Ricardo S. Bernardes ${ }^{1}$

Oscar de M. Cordeiro Netto 1

\footnotetext{
1 Departamento de Engenharia Civil e Ambiental, Faculdade de Tecnologia Universidade de Brasília. Brasília, DF 70910-900, Brasil.
}

\begin{abstract}
The understanding of sanitation infrastructure, public health, and environmental relations is a fundamental assumption for planning sanitation infrastructure in urban areas. This article thus suggests elements for developing a planning model for sanitation infrastructure. The authors performed a historical survey of environmental and public health issues related to the sector, an analysis of the conceptual frameworks involving public health and sanitation systems, and a systematization of the various effects that water supply and sanitation have on public health and the environment. Evaluation of these effects should guarantee the correct analysis of possible alternatives, deal with environmental and public health objectives (the main purpose of sanitation infrastructure), and provide the most reasonable indication of actions. The suggested systematization of the sanitation systems effects in each step of their implementation is an advance considering the association between the fundamental elements for formulating a planning model for sanitation infrastructure.
\end{abstract}

Key words Sanitation; Planning; Environment and Public Health

Resumo A compreensão das relações entre saneamento, saúde pública e meio ambiente revelase um pressuposto fundamental para o planejamento de sistemas de saneamento em centros urbanos. Nesse sentido, o presente artigo objetiva propor elementos para o desenvolvimento de um modelo de planejamento em saneamento, a partir de um levantamento histórico das questões ambientais e de saúde incorporadas pelo setor, de uma análise dos marcos conceituais da relação saúde e saneamento, e de uma sistematização dos diversos efeitos da implementação de sistemas de abastecimento de água e de esgotamento sanitário no meio ambiente e na saúde pública. A avaliação desses efeitos deve garantir a análise correta das possíveis alternativas, tanto do ponto de vista dos objetivos ambientais, quanto dos de saúde pública (objeto primordial do saneamento), de modo a apontar o direcionamento mais adequado das ações. A proposta de sistematização dos efeitos das ações de saneamento em cada fase de sua implementação, realizada neste trabalho, constitui-se em um avanço, no sentido de reunir elementos fundamentais para a formulação de um modelo de planejamento em saneamento.

Palavras-chave Saneamento; Planejamento; Meio Ambiente e Saúde Pública 


\section{Introdução}

Nos últimos anos, tem-se observado que a finalidade dos projetos de saneamento tem saído de sua concepção sanitária clássica, recaindo em uma abordagem ambiental, que visa não só a promover a saúde do homem, mas, também, a conservação do meio físico e biótipo. Com isso, a avaliação ambiental dos efeitos dos sistemas de saneamento nas cidades consolidou-se como uma etapa importante no processo de planejamento, no que se refere à formulação e seleção de alternativas e à elaboração e detalhamento dos projetos selecionados. A avaliação da viabilidade ambiental assume caráter de forte condicionante das alternativas a serem analisadas, ocorrendo, muitas vezes, a predominância dos critérios ambientais em relação, por exemplo, aos critérios econômicos (Pimentel \& Cordeiro Netto, 1998). Por outro lado, verifica-se a ausência de instrumentos de planejamento relacionados à saúde pública, constituindo, no Brasil, uma importante lacuna em programas governamentais no setor de saneamento (Heller, 1997).

A compreensão dessas diversas relações revela-se um pressuposto fundamental para o planejamento dos sistemas de saneamento em centros urbanos, de modo a privilegiar os impactos positivos sobre a saúde pública (objeto primordial das ações) e sobre o meio ambiente. Ressalta-se que apesar do conceito de saneamento compreender os sistemas de abastecimento de água e esgotamento sanitário, a coleta e disposição de resíduos sólidos, a drenagem urbana e o controle de vetores, considerou-se, neste trabalho, apenas os sistemas de água e esgotos. No entanto, essa opção metodológica não descarta a importância das demais ações de saneamento, que também devem ser incorporadas oportunamente, na formulação de um modelo de planejamento integrado.

Quando se fala da implementação de sistemas de abastecimento de água e de esgotamento sanitário, e dos benefícios à saúde pública e ao meio ambiente, deve-se esclarecer algumas questões: os benefícios à saúde e ao meio ambiente são obtidos com o mesmo tipo de intervenção? Quais os efeitos negativos quando da implementação desses sistemas? Como são integradas as duas dimensões de análise, a ambiental e a sanitária? O fortalecimento da consciência ambiental, com a mudança de paradigmas, retirou o foco de interesse na área de saúde pública?

Apesar dessas questões já estarem conceitualmente resolvidas para os especialistas da área de saneamento, meio ambiente e saúde, a formulação e a clareza dessas respostas são fun- damentais na etapa de planejamento. Assim, com o propósito de proceder a uma avaliação dos efeitos das ações de saneamento, o presente trabalho objetiva, primeiramente, traçar um breve panorama histórico de como as questões de saúde e meio ambiente foram incorporadas pelo setor de saneamento. Em seguida, faz-se uma análise dos marcos conceituais da relação saúde e saneamento e uma sistematização, com base em levantamento bibliográfico, dos diversos efeitos, no meio ambiente e na saúde pública, da implementação de sistemas de água e esgotos em áreas urbanas. A partir dessas considerações, são propostos elementos para a construção de um modelo de planejamento em saneamento.

\section{A evolução histórica}

A Tabela 1 apresenta um panorama histórico dos aspectos de saúde pública e meio ambiente que nortearam o setor de saneamento, desde meados do século XIX até o início do século XXI. Pode-se observar que a própria evolução do conceito de saúde pública e sua interface com o saneamento, o fortalecimento da questão ambiental e os aspectos referentes à legislação de controle de qualidade da água, seja ela para o abastecimento público ou para o controle da poluição, são condutores das ações de saneamento. Como observado por Branco (1991), a história brasileira é toda pontuada por aspectos institucionais e de regulação sobre a qualidade das águas, que se modificaram na medida em que os conceitos de saúde e meio ambiente foram sendo incorporados.

Na Tabela 1, percebe-se que o enfoque eminentemente sanitarista, em que o saneamento é uma ação de saúde pública, prevaleceu durante vários anos, mesmo não havendo um consenso científico quanto aos benefícios advindos da implementação dos sistemas de água e esgotos (Cairncross, 1989; Heller, 1997). A avaliação ambiental, incorporada recentemente, inclui novas questões quando da implementação dos sistemas de saneamento, tanto com relação ao seus efeitos positivos como também negativos.

Com efeito, embora saúde e higiene tenham sido motivos de preocupações em políticas urbanas na América Latina desde meados do século XIX, somente nos últimos anos o acesso aos sistemas de abastecimento de água e de esgotamento sanitário passou a ser considerado como tema ambiental, inclusive no Brasil.

Deve-se ressaltar, no entanto, que apesar dessa mudança de enfoque, os objetivos ambientais e de saúde não são exatamente os mesmos, o que fica evidenciado, por exemplo, quan- 
Evolução histórica dos aspectos de saúde pública e meio ambiente no setor de saneamento no Brasil.

\section{Período}

\section{Principais características}

Meados do século XIX até início do século $X X$

- Estruturação das ações de saneamento sob o paradigma do higienismo, isto é, como uma ação de saúde, contribuindo para a redução da morbi-mortalidade por doenças infecciosas, parasitárias e até mesmo não infecciosas.

- Organização dos sistemas de saneamento como resposta a situações epidêmicas, mesmo antes da identificação dos agentes causadores das doenças.

Início do século XX até a década de 30

Décadas de 30 e 40

Décadas de 50 e 60

Década de 70

Década de 80

Década de 90 até o início do século XXI
- Intensa agitação política em torno da questão sanitária, com a saúde ocupando lugar central na agenda pública: saúde pública em bases científicas modernas a partir das pesquisas de Oswaldo Cruz.

- Incremento do número de cidades com abastecimento de água e da mudança na orientação do uso da tecnologia em sistemas de esgotos, com a opção pelo sistema separador absoluto, em um processo marcado pelo trabalho de Saturnino de Brito, que defendia planos estreitamente relacionados com as exigências sanitárias (visão higienista).

- Elaboração do Código das Águas (1934), que representou o primeiro instrumento de controle do uso de recursos hídricos no Brasil, estabelecendo o abastecimento público como prioritário.

- Coordenação das ações de saneamento (sem prioridade) e assistência médica (predominante) essencialmente pelo setor de saúde.

- Surgimento de iniciativas para estabelecer as primeiras classificações e os primeiros parâmetros físicos, químicos e bacteriológicos definidores da qualidade das águas, por meio de legislações estaduais e em âmbito federal.

- Permanência da dificuldade em relacionar os benefícios do saneamento com a saúde, restando dúvidas inclusive quanto à sua existência efetiva.

- Predomínio da visão de que avanços nas áreas de abastecimento de água e de esgotamento sanitário nos países em de senvolvimento resultariam na redução das taxas de mortalidade, embora ausentes dos programas de atenção primária à saúde. incremento dos índices de atendimento por istemas de abastecimento de água.

- Inserção da preocupação ambiental na agenda política brasileira, com a consolidação dos conceitos de ecologia e meio ambiente e a criação da Secretaria Especial de Meio

- Formulação mais rigorosa dos mecanismos responsáveis pelo comprometimento das condições de saúde da população, na ausência de condições adequadas de saneamento (água e esgotos).

- Instauração de uma série de instrumentos legais de âmbito nacional definidores de políticas e ações do governo brasileiro, como a Política Nacional do Meio Ambiente (1981).

- Revisão técnica das legislações pertinentes aos padrões de qualidade das águas.

- Ênfase no conceito de desenvolvimento sustentável e de preservação e conservação do meio ambiente e particularmente dos recursos hídricos, refletindo diretamente no planejamento das ações de saneamento.

- Instituição da Política e do Sistema Nacional de Gerenciamento de Recursos Hídricos (Lei 9.433/97).

- Incremento da avaliação dos efeitos e conseqüências de atividades de saneamento que importem impacto ao meio ambiente.
- Consolidação do Plano Nacional de Saneamento (PLANASA), com ênfase no Ambiente (SEMA) em 1973.

Fonte: Branco (1991), Cairncross (1989), Costa (1994) e Heller (1997). 
do se examinam os padrões de qualidade da água relacionados aos aspectos de proteção do corpo receptor e ao aspecto de potabilidade, diretamente associado à qualidade da água fornecida ao consumidor (Lijklema, 1995; Nascimento \& von Sperling; 1998).

Com os avanços incorporados na área de saneamento e controle da poluição nas últimas décadas, evidenciou-se a necessidade de se proceder a revisão técnica da legislação, em face dos padrões de qualidade da água que se queria estabelecer. Com efeito, no final dos anos 80, começaram a ser elaboradas e revisadas as legislações pertinentes aos padrões de qualidade das águas, a exemplo da Resolução 20/86 (Brasil, 1986) do Conselho Nacional do Meio Ambiente (CONAMA), que, entre outros objetivos, busca a proteção das águas dos mananciais, e da Portaria no 36/90 do Ministério da Saúde (MS, 1990), que estabelece normas e padrões para a qualidade da água de consumo humano.

A Portaria no 36/90 deve continuar em vigor somente durante o período de transição para a vigência da nova portaria do MS, a de no 1.469/ 2000 (MS, 2000), que revisou os padrões de potabilidade e os procedimentos relativos ao controle e vigilância da qualidade da água para o consumo humano. Segundo Bastos et al. (2001), essa portaria pretendeu incorporar ao máximo as informações recentes sobre os riscos associados, por exemplo, à Giardia lamblia, Cryptosporidium sp. e cianobactérias; os mecanismos de remoção de patogênicos por meio do tratamento de água; o emprego de indicadores e as evidências toxicológicas de agravos à saúde decorrentes da ingestão de substâncias químicas.

Ao contrário dos padrões de potabilidade, que versam quase que exclusivamente sobre aspectos relacionados com a saúde humana, com pouca relação com o meio ambiente, os padrões de qualidade ambiental levam em conta, essencialmente, alterações do teor de oxigênio, de matéria orgânica, de nutrientes, do pH e da temperatura, do curso d'água, isso é, possuem um enfoque ambiental. Os parâmetros citados não acarretam, na maior parte das vezes, prejuízos diretos ao homem, pois as doenças infecciosas, provenientes da poluição hídrica, são, normalmente, o resultado de uma ação mais direta de contágio de uma pessoa para outra.

\section{Marcos conceituais da relação saneamento e saúde pública}

Do estrito ponto de vista da engenharia, o que se avalia em um organismo patogênico não é a sua natureza biológica, nem o seu comporta- mento no corpo do doente, e sim o seu comportamento no meio ambiente, pois é nessa dimensão que as intervenções de saneamento podem influenciar na ação desse patogênico sobre o homem (Cairncross, 1984). Dessa forma, para uma melhor compreensão do problema, dois tipos de estudos se mostram pertinentes (Heller, 1997). O primeiro diz respeito aos modelos que têm sido propostos para explicar a relação entre ações de saneamento e a saúde, com ênfase em distintos ângulos da cadeia causal. O segundo tipo de análise, consiste em classificar as doenças segundo categorias ambientais cuja transmissão está ligada com o saneamento, ou com a falta de infra-estrutura adequada. Assim, a partir dessas classificações, o entendimento da transmissão das doenças relacionadas com o saneamento passa a constituir um instrumento de planejamento das ações, com vistas a considerar de forma mais adequada seus impactos sobre a saúde do homem.

Estudando as várias vias de contaminação de doenças, como no caso das diarréias e da incidência de cólera, Briscoe $(1984,1987)$ desenvolveu um modelo para a compreensão do efeito obtido após a eliminação de apenas parte das múltiplas vias de transmissão de uma determinada doença. O modelo infere que a obstrução de uma importante via de transmissão, pode redundar em uma redução muito inferior à originalmente esperada quanto à probabilidade de infecção. Verifica-se, pelos estudos, que a implementação de sistemas de abastecimento de água e de esgotamento sanitário é condição necessária, mas não suficiente para se garantir a eliminação dessas doenças. Briscoe (1987) afirma, ainda, que esses sistemas apresentam efeitos de longo prazo sobre a saúde bem maiores do que os efeitos provenientes de intervenções médicas, o que o leva a sugerir um efeito multiplicador da ação dos sistemas de água e esgotos. Esse efeito, se devidamente confirmado, é um importante aspecto a ser levado em consideração quando do planejamento de sistemas de saneamento, pois indica uma intervenção potencial de longo prazo.

Com um outro enfoque, o estudo de Cvjetanovic (1986), parte para uma visão mais abrangente sobre a questão da saúde, agregando fatores sociais e econômicos. Esquematicamente, a Figura 1 ilustra o modelo proposto pelo autor, no qual se prevê que sistemas de abastecimento de água e de esgotamento sanitário proporcionam benefícios gerais sobre a saúde da população segundo duas vias: mediante efeitos diretos e efeitos indiretos, resultantes, primordialmente, do nível de desenvolvimento da localidade atendida. Segundo Heller (1997), embora tenha plei- 
Esquema conceitual dos efeitos diretos e indiretos do abastecimento de água

e do esgotamento sanitário sobre a saúde.
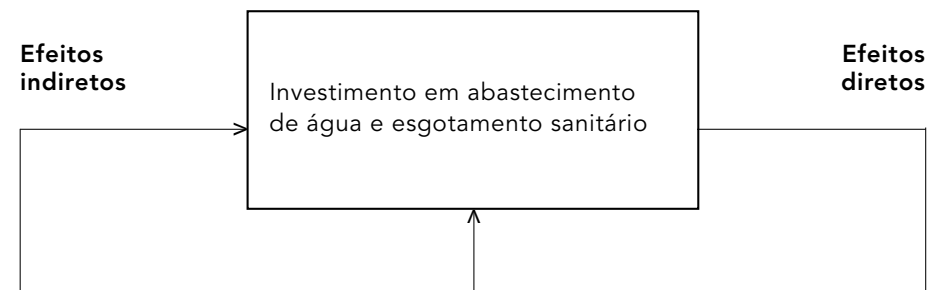

Abastecimento de água seguro e disposição de excretas

Manutenção e expansão

Qualidade
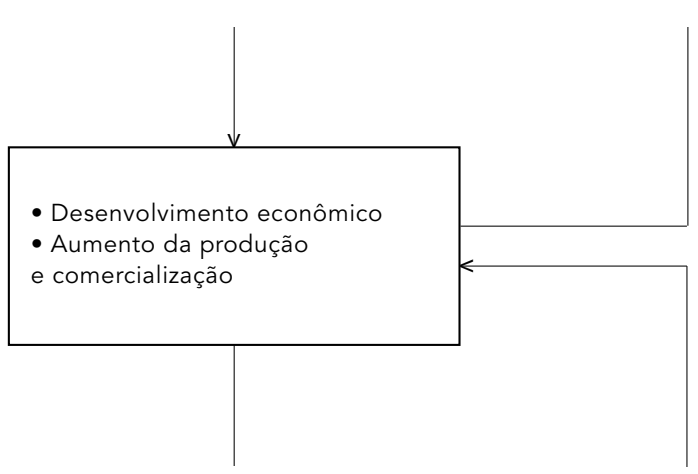

Educação; Alimentação;

Capacidade de trabalho Instalações sanitárias e de aprendizagem

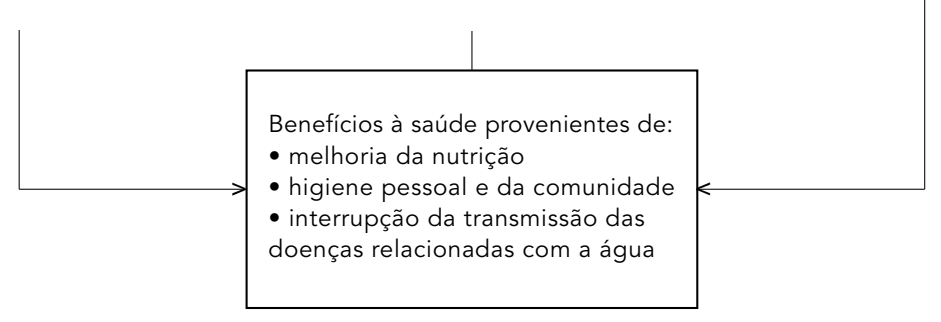

Fonte: Cvjetanovic (1986).

teado uma explicação causal mais sistêmica, o modelo de Cvjetanovic (1986), não considera o papel dos determinantes sociais.

Essa tentativa é feita, por exemplo, pela teoria do limiar e saturação, desenvolvida por Shuval et al. (1981), que procuraram explicar a influência do nível sócio-econômico da população sobre a relação entre as condições de saneamento e saúde. Supõe-se que exista um limiar sócio-econômico e de saúde, abaixo do qual os investimentos em saneamento não resultam em benefícios concretos e um limite superior, de saturação, acima do qual um próximo investimento não produz novos benefícios sobre a saúde. Segundo Briscoe (1987) e Heller
(1997), a alegação do limiar pode ser contestada por estudos epidemiológicos realizados em diversos países pobres, especialmente africanos e asiáticos, que demonstraram importantes impactos sobre indicadores diversos de saúde a partir de intervenções em saneamento. Entretanto, nessas situações, não se pode desconsiderar os efeitos provenientes da educação sanitária e ambiental, de noções de higiene e do aspecto cultural (Gomes, 1995).

A partir da década de 70, foram iniciados esforços no sentido de estudar as doenças infecciosas, sob o enfoque das estratégias mais adequadas para o seu controle, e sua relação com o meio ambiente (Heller, 1997). Ao longo dos anos, 
vários estudos foram desenvolvidos (Cairncross, 1984; Cairncross \& Feachem, 1990; Feachem et al., 1983; Mara \& Alabaster, 1995; White et al., 1972), de modo a classificar ambientalmente as doenças, com base em suas vias de transmissão e seu ciclo. Esse tipo de classificação tem maior aplicabilidade para o engenheiro, ao contrário da classificação biológica clássica, que agrupa as doenças segundo o agente: vírus, bactérias, protozoários ou helmintos.

Em revisão dos estudos anteriores, Mara \& Feachem (1999) propõem uma classificação ambiental unitária das infecções relacionadas com a água e com os excretas, agrupadas em sete categorias, como indicado na Tabela 2.

Segundo Mara \& Feachem (1999), a classificação unitária por eles proposta é um avanço em relação às classificações individuais existentes, que separam as doenças relacionadas com a água das relacionadas com os excretas. Isso se deve ao fato de a maioria das doenças estarem relacionadas com ambos os elementos, de forma que a implementação integrada e a correta manutenção e operação de sistemas de abastecimento de água e de esgotamento sanitário, constituem a melhor forma de controle dessas doenças em um longo prazo.

A partir dos modelos conceituais e da classificação ambiental das doenças que podem estar relacionadas, de alguma forma, com o saneamento, pode-se antecipar os efeitos das intervenções de saneamento na saúde pública e ainda inferir sobre as possíveis relações com o meio ambiente. Cabe ao planejamento indicar quais as medidas que estão relacionadas e quais são as ações independentes, de modo a direcionar a forma mais eficaz de implementação dos sistemas de abastecimento de água e de esgotamento sanitário, com vistas à melhoria tanto da saúde pública, quanto do meio ambiente. Para tanto, é necessário identificar os efeitos, positivos e negativos, quando da implementação desses sistemas de saneamento.

\section{Efeitos das intervenções de saneamento}

Os efeitos prováveis decorrentes de um sistema de abastecimento de água são geralmente positivos, por constituir um serviço que assegura melhoria e bem-estar da população (Cairncross, 1989; VanDerslice \& Briscoe, 1995). O benefício oferecido pelo tratamento de água, por exemplo, é indiscutível, pois transforma, após a remoção de contaminantes, água inadequada para o consumo humano em um produto que esteja em acordo com padrões de potabilidade. No entanto, o tratamento implica na uti- lização de substâncias químicas que podem afetar a saúde daqueles que a utilizam.

Segundo Daniel et al. (1990), os riscos relacionados ao processo de cloração, substância química mais empregada no processo de tratamento da água, estão associados muito mais aos seus subprodutos (p.e. trialometanos) do que aos agentes utilizados. Em revisão elaborada por Tominaga \& Midio (1999), observou-se, a partir de dados epidemiológicos, que os subprodutos da cloração podem aumentar a incidência de certos tipos de câncer na população humana. Processos alternativos de desinfecção da água, que evitam a formação dos trialometanos, são aqueles que não utilizam cloro livre (tais como ozonização e radiação ultravioleta), entretanto, esses também podem levar à formação de outros subprodutos, conforme o teor de matéria orgânica presente na água, sendo que seus efeitos na saúde humana ainda não foram completamente avaliados.

Além dos riscos à saúde, o processo de tratamento de água convencional também pode causar danos ambientais. No Brasil, de acordo com Cordeiro (2000), a água de lavagem dos filtros e dos tanques de preparação de soluções e suspensões de produtos químicos, e o lodo dos decantadores tradicionais são resíduos do processo de tratamento, que são dispostos, com grande freqüência, nos mananciais próximos às estações de tratamento de água (ETAs). Como a toxicidade potencial desses resíduos depende de inúmeros fatores, tais como a utilização de determinados produtos químicos (com destaque para o sulfato de alumínio, muito empregado no processo de coagulação e floculação da água), faz-se necessário maior cuidado com a sua disposição, de modo a evitar maiores prejuízos ao meio ambiente.

No sistema de produção de água, impactos ambientais negativos também podem ocorrer na captação da água bruta (Tchobanoglous \& Schroeder, 1985), com alteração do regime hidrológico, principalmente de pequenos mananciais, e decréscimo do nível do lençol freático em captações subterrâneas. Com relação à distribuição de água potável, resultados compilados por Esrey et al. (1991), por exemplo, demostram uma eficiência média de $30 \%$ na redução da incidência de doenças infecciosas intestinais e helmintíases (categoria A, Tabela 2), decorrente da implementação de sistema de abastecimento de água. No entanto, mesmo os impactos positivos esperados devem ser vistos com parcimônia, pois a qualidade bacteriológica da água distribuída e consumida pela população nem sempre atende aos padrões de potabilidade (Moraes et al., 1999). Segundo Van- 
Classificação ambiental unitária das infecções relacionadas com o saneamento (água e excretas).

\begin{tabular}{|c|c|}
\hline Categoria & Estratégias de controle e exemplos (organismo ou doença) \\
\hline $\begin{array}{l}\text { A - Doenças do tipo feco-oral } \\
\text { (transmissão hídrica ou relacionada } \\
\text { com a higiene) }\end{array}$ & $\begin{array}{l}\text { - Melhora da quantidade, disponibilidade e confiabilidade da água } \\
\text { (abastecimento de água), no caso das doenças relacionadas com a } \\
\text { higiene; } \\
\text { - Melhora da qualidade da água (tratamento de água), para as doenças } \\
\text { de transmissão hídrica; } \\
\text { - Educação sanitária. } \\
\text { Ex.: Hepatite A, E e F, Poliomielite, Cólera, Disenteria bacilar, Amebíase, } \\
\text { Diarréia por Escherichia coli e rotavírus, Febre tifóide, Giardíase e Ascaridíase. }\end{array}$ \\
\hline $\begin{array}{l}\text { B - Doenças do tipo não feco-oral } \\
\text { (relacionadas com a higiene) }\end{array}$ & $\begin{array}{l}\text { - Melhora da quantidade, disponibilidade e confiabilidade da água } \\
\text { (abastecimento de água); } \\
\text { - Educação sanitária. } \\
\text { Ex.: doenças infecciosas da pele e dos olhos e febre transmitida } \\
\text { por pulgas. }\end{array}$ \\
\hline C - Helmintíases do solo & $\begin{array}{l}\text { - Tratamento dos excretas ou esgotos antes da aplicação no solo; } \\
\text { - Educação sanitária. } \\
\text { Ex.: Ascaridíase e Ancilostomose. }\end{array}$ \\
\hline D - Teníases & $\begin{array}{l}\text { - Como na categoria C, mais cozimento e inspeção da carne. } \\
\text { Ex.: Teníases }\end{array}$ \\
\hline E - Doenças baseadas na água & $\begin{array}{l}\text { - Diminuição do contato com águas contaminadas; } \\
\text { - Melhora de instalações hidráulicas; } \\
\text { - Sistemas de coleta de esgotos e tratamento dos esgotos antes } \\
\text { do lançamento ou reuso; } \\
\text { - Educação sanitária. } \\
\text { Ex.: Leptospirose e Esquistossomose. }\end{array}$ \\
\hline $\begin{array}{l}\text { F - Doenças transmitidas } \\
\text { por inseto vetor }\end{array}$ & $\begin{array}{l}\text { - Identificação e eliminação dos locais adequados para procriação; } \\
\text { - Controle biológico e utilização de mosquiteiros } \\
\text { - Melhora da drenagem de águas pluviais. } \\
\text { Ex.: Malária, Dengue, Febre amarela, Filariose e infecções transmitidas } \\
\text { por baratas e moscas relacionadas com excretas. }{ }^{*}\end{array}$ \\
\hline $\begin{array}{l}\text { G - Doenças relacionadas com } \\
\text { vetores roedores }\end{array}$ & $\begin{array}{l}\text { - Controle de roedores } \\
\text { - Educação sanitária; } \\
\text { - Diminuição do contato com águas contaminadas. } \\
\text { Ex.: Leptospirose e doenças transmitidas por vetores roedores. * }\end{array}$ \\
\hline
\end{tabular}

* Infecções excretadas compreendem todas as doenças nas Categorias A, C e D

e as doenças por helmintos na Categoria E.

Fonte: Mara \& Feachem (1999).

Derslice \& Briscoe (1993), o comprometimento da qualidade da água distribuída constitui um fator de risco bem maior do que a água contaminada na própria residência, pois introduz novos organismos patogênicos ao meio, o que reforça, de acordo com Hunter (2001), a necessidade de se ampliar a discussão sobre o monitoramento direto desses organismos.

A qualidade da água de uma rede de abastecimento está fortemente relacionada ao seu regime de distribuição, às características de projeto e operação do sistema de abastecimento (Clark \& Coyle, 1990), e à localização do empreendimento no que diz respeito à vulnerabilidade da área de influência (Pimentel \& Cordeiro Netto, 1998). Isso leva uma parcela considerável da população a ser abastecida com águas eventualmente contaminadas, utilizando-se de fontes alternativas (e nem sempre confiáveis) para o consumo ou encontrando-se em áreas com regime deficiente de abastecimento (Alaburda \& Nishihara, 1998).

A contaminação da água nos sistemas de abastecimento se dá, portanto, pela associação de diversos fatores, tais como: a descontinuidade do fornecimento, que determina pressões negativas na rede; a falta de esgotamento sanitário; a presença de baixas pressões na rede, por problemas operacionais ou de projeto e a manutenção inadequada da rede, dos reservatórios de distribuição e, principalmente, das ligações domiciliares de água (d’Aguila et al., 2000). 
Cairncross \& Kolsky (1997) e Esrey et al. (1991) apontam, entretanto, que não só a qualidade, mas, principalmente, a quantidade de água disponível para consumo possui um impacto preponderante na saúde das pessoas, sendo fator a ser considerado quando da etapa de planejamento. Esrey (1996), entretanto, considera que a melhoria das condições de esgotamento sanitário possui um maior benefício à saúde, como por exemplo na redução da incidência de diarréias (categoria A, Tabela 2), do que os sistemas de abastecimento de água, posição esta questionada por Cairncross \& Kolsky (1997).

Os resultados de Gerolomo \& Penna (2000), apontam, embora de maneira cautelosa, que instalações sanitárias, sem destino adequado do esgoto, constituem-se em fator de risco para disseminação da cólera (categoria A, Tabela 2). Isso reforça a tese de Cairncross \& Kolsky (1997), segundo a qual as prioridades em termos de saneamento são a oferta de água de boa qualidade e em quantidade suficiente, necessária para o bom funcionamento das instalações sanitárias e o afastamento dos esgotos, quando existir uma rede coletora ou fossa séptica.

No caso do sistema de esgotamento sanitário, apesar dos benefícios à saúde pública, com o afastamento dos esgotos da proximidade das residências, existem significativos impactos negativos quando da sua implementação. O principal aspecto negativo desse tipo de sistema, além de possíveis vazamentos, é a concentração da poluição nas redes coletoras. Caso não possua tratamento adequado, o sistema de esgotamento sanitário poderá induzir a uma deterioração do corpo receptor (rios, lagos, lagoas, represas, enseadas, baías e mares), inviabilizar a vida aquática e ainda prejudicar outros usuários da água ou outras espécies de animais e vegetais (Pimentel \& Cordeiro Netto, 1998; Tchobanoglous \& Schroeder, 1985).

O comprometimento do corpo receptor é um agravante tanto ambiental quanto sanitário e se reflete mesmo quando ocorre o tratamento dos esgotos. Estudos desenvolvidos por von Sperling \& Chernicharo (2000) indicam que as tecnologias de tratamento de esgotos empregadas no Brasil são eficientes somente no que se refere à remoção de Demanda Bioquímica de Oxigênio (DBO), Demanda Química de Oxigênio (DQO) e Sólidos em Suspensão (SS). Entretanto, não produzem um efluente compatível com os padrões de qualidade exigidos pela legislação, em termos de amônia, nitrogênio, coliformes fecais e, principalmente, fósforo. Com esses dados, percebe-se um significativo distanciamento entre os objetivos alcançados no tratamento de esgotos no Brasil e os já atingidos em países desenvolvidos, apresentados na Tabela 3.

A análise da Tabela 3 indica que o tratamento de esgotos no Brasil somente atinge hoje, em parte, os objetivos dos países desenvolvidos anteriores à década de 70, pois ainda existe um déficit com relação a soluções para a eliminação de organismos patogênicos. Por outro lado, os países desenvolvidos já possuem preocupações avançadas com a proteção ambiental e os riscos à saúde pública que se refletem, por exemplo, nos cuidados com o manejo do lodo produzido em estações biológicas de tratamento de esgotos.

No Brasil, uma alternativa que pode ser adotada como forma de planejamento é a garantia da qualidade do efluente por etapas (von Sperling \& Chernicharo, 2000), afigurando-se, assim, como uma solução prática no sentido de viabilizar um atendimento gradativo aos padrões de qualidade da água e aos objetivos do tratamento de esgotos. Essa evolução gradual da qualidade do efluente tratado deve permitir, além da redução dos custos de implantação da Estação de Tratamento de Esgotos (ETE), a adoção de novas alternativas tecnológicas, mesmo com mudanças na concepção original proposta para o tratamento. De certo modo, pode ser retratada também como a evolução histórica apresentada na Tabela 3, que possibilitou o atendimento gradual aos padrões ambientais e sanitários.

\section{Elementos para desenvolvimento de um modelo de planejamento}

Diante das considerações anteriores, apresentase uma sistematização dos efeitos positivos e negativos advindos da implementação de sistemas de abastecimento de água e de esgotamento sanitário em áreas urbanas (Figura 2), com o objetivo de esclarecer as inter-relações entre saneamento, saúde pública e meio ambiente.

Com relação ao modelo de efeitos apresentado na Figura 2, algumas observações são importantes: (a) o modelo não pretende representar um conjunto exaustivo dos efeitos, muito menos definitivo, apresentando, apenas, uma visão da multiplicidade dos efeitos em face das intervenções em saneamento; (b) os efeitos considerados não são equivalentes, sendo que os mais significativos encontram-se assinalados; (c) os efeitos apresentados são resultados das etapas dos sistemas como usualmente projetadas e implementadas; (d) os impactos referentes ao meio ambiente são relacionados exclusivamente com os recursos hídricos, sua flora e fauna, não sendo considerados os impactos no resto do ecossistema. 
Evolução dos objetivos do tratamento de esgotos em países desenvolvidos.

\begin{tabular}{|c|c|}
\hline Período & Objetivos do tratamento de esgotos \\
\hline $\begin{array}{l}\text { Início do século } X X \\
\text { até a década de } 70\end{array}$ & $\begin{array}{l}\text { - Remoção de sólidos em suspensão (SS). } \\
\text { - Tratamento da matéria orgânica (remoção de DBO e DQO). } \\
\text { - Eliminação de organismos patogênicos. }\end{array}$ \\
\hline Décadas de 70 e 80 & $\begin{array}{l}\text { - Preocupação principal com aspectos estéticos e ambientais do efluente. } \\
\text { - Remoção de DBO, SS e patogênicos continua com níveis mais elevados. } \\
\text { - Remoção de nutrientes (nitrogênio e fósforo) começa a ser incorporada. }\end{array}$ \\
\hline A partir da década de 80 & $\begin{array}{l}\text { - Preocupação com os riscos à saúde relacionados com compostos químicos } \\
\text { tóxicos ou potencialmente tóxicos lançados no meio ambiente. } \\
\text { - Permanência dos objetivos de melhoria da qualidade da água dos anos } \\
\text { anteriores, porém com a mudança de ênfase para a definição e remoção } \\
\text { de compostos tóxicos que podem causar efeitos na saúde humana } \\
\text { em longo prazo. }\end{array}$ \\
\hline
\end{tabular}

Fonte: Metcalf \& Eddy Incorporation (1991).

Em se tratando de projetos de grandes dimensões, como a implementação de sistemas de saneamento em extensas áreas urbanas, a integração da avaliação desses efeitos na etapa de planejamento deve ser imprescindível, visando a garantir a implementação adequada das ações, tanto do ponto de vista dos objetivos ambientais, quanto dos de saúde pública.

Em muitos casos, mesmo com o investimento feito em ações de saneamento, não ocorrem os impactos positivos esperados, independente do tipo de sistema implementado. Por um lado, deficiências de projeto e dos serviços de manutenção e operação contribuem para essa situação, por outro, a ausência de ações integradas de água e esgotos, dentre outras, constitui o fator dominante para a minimização ou eliminação dos efeitos positivos, como pode ser observado nas inter-relações apresentadas na Figura 2.

Sem dúvida, vários estudos dos efeitos das ações de saneamento confirmam a evidência de que a implementação de sistemas de abastecimento de água e de esgotamento sanitário causam benefícios à saúde pública e ao meio ambiente. Uma questão que permanece indefinida, no entanto, é o conhecimento do comportamento dos diferentes efeitos ao se compararem realidades diferentes, uma vez que os fatores envolvidos nessa questão podem ser bastante dinâmicos e muito variáveis de uma realidade à outra.

Dentre os vários fatores, um está relacionado com a existência de dois domínios de transmissão de doenças, o domínio público e o doméstico (Cairncross et al., 1996), sendo fundamental essa distinção em se tratando de saneamento. Segundo os autores, a divisão em dois domínios é importante na medida em que o controle da transmissão de cada tipo exige intervenções diferentes. As doenças infecciosas que podem ser combatidas pelo saneamento se transmitem, geralmente, em ambos os domínios. Assim, mesmo que, de forma ampla, o saneamento só atue no domínio público, é necessário atender às necessidades do domínio doméstico, para que se dê a eliminação de toda transmissão evitável de doenças infecciosas. Algumas vezes, os benefícios nem sempre são resultantes diretos de ações de saneamento, mas sim decorrentes da nova relação ambiental e dos hábitos de comportamento e higiene que se estabelecem (Esrey et al., 1991; Gomes, 1995; VanDerslice \& Briscoe, 1995).

\section{Considerações finais}

A compreensão das relações entre saneamento, saúde pública e meio ambiente constitui etapa inicial e importante no desenvolvimento de um modelo de planejamento de sistemas de abastecimento de água e de esgotamento sanitário. Em termos de planejamento, a identificação e análise dos efeitos advindos da implementação de determinado sistema, seja ele de água ou de esgotos, deve conferir meios para se estabelecer uma certa ordem de prioridades e apontar o direcionamento mais adequado das ações, uma vez que cada população a ser beneficiada possui características distintas e nem sempre as ações de saneamento podem ser orientadas da mesma forma.

Assim, os impactos positivos e negativos devem sempre ser verificados quanto à sua real 
Figura 2

Modelo de efeitos diretos na saúde e no meio ambiente provenientes da implementação de sistemas de água e esgotos.

\section{Efeitos Negativos}

Meio Ambiente

- alteração do regime

hidrológico do

manancial

- disposição do lodo

dos decantadores e

da água de lavagem

dos filtros de ETA

- sem efeitos nega-

tivos relevantes

- Concentração

dos esgotos na rede coletora sem disposição

final adequada

- degradação

e possibilidade de

eutrofização do corpo

receptor

- disposição do lodo produzido nas etapas de tratamento de ETE
Saúde Pública

- exposição aos subprodutos do processo de tratamento (p.e. trialometanos) ção da água, devido a problemas de projeto ou operação da rede de distribuição (p.e. pressões negativas)

- Comprometimento da qualidade das águas que podem vir a ser utilizadas (p.e. para o abastecimento) do lodo produzido, sem tratamento adequado, oferecem riscos à saúde em função da presença de agentes patogênicos

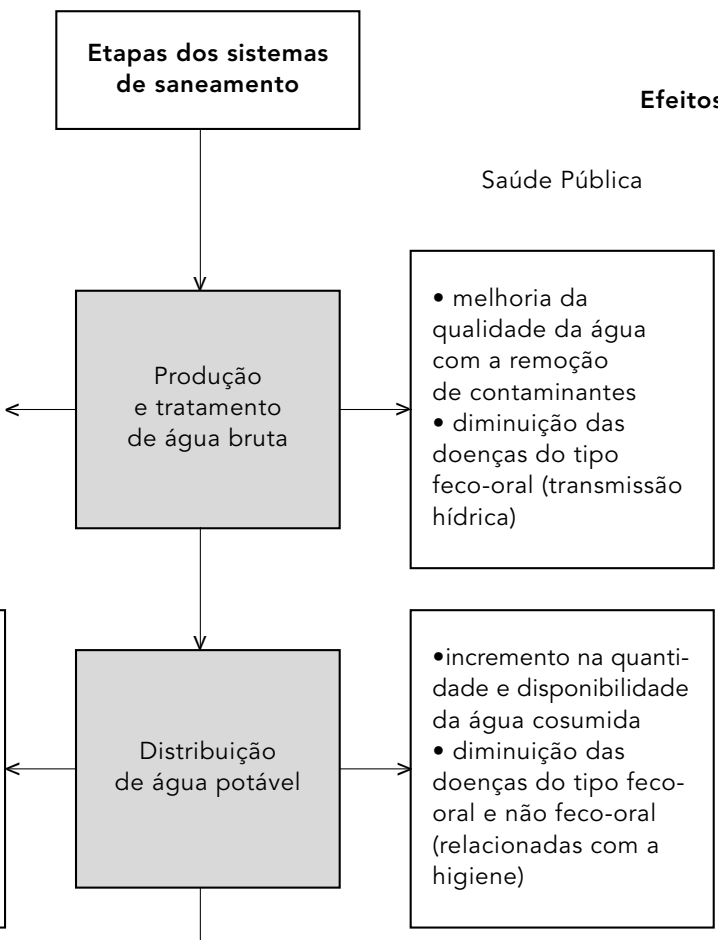

Domicílio urbano
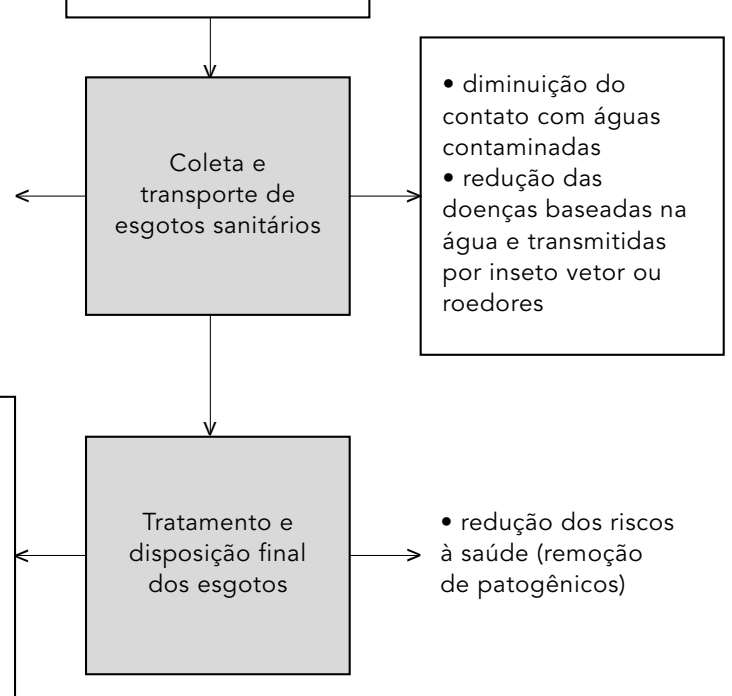

- sem efeitos positivos relevantes

- redução do uso indevido dos recursos hídricos como fonte de abastecimento
- redução do risco de contaminação de aquíferos subterrâneos
- diminuição da degradação do corpo receptor (remoção de matéria orgânica) - diminuição do risco de eutrofização (remoção de nutrientes)

Efeitos julgados mais significativos 
ocorrência e dimensão, na tentativa de se estabelecerem efeitos comparativos entre realidades diferentes, de modo a propiciar a avaliação correta das possíveis alternativas. Nesse sentido, a proposta deste trabalho de sistematização dos efeitos no meio ambiente e na saúde pública, em cada fase da implementação de ações de saneamento, constitui-se em um avanço, no sentido de reunir elementos para um modelo de planejamento em saneamento.

No entanto, não só os aspectos relacionados ao meio ambiente e à saúde pública devem ser levados em consideração. No caso do sanea- mento, existem diferentes dimensões, em níveis crescentes de complexidade, a serem consideradas na definição de uma solução apropriada, como a econômica, financeira, social, institucional e a política, o que torna mais difícil, ainda, o desenvolvimento de um modelo. A construção teórica a ser desenvolvida para o modelo de planejamento deve, desse modo, contrapor-se a estudos de caso, que permitam verificar a pertinência dos elementos e processos propostos, subsidiando, assim, a formulação do modelo.

\section{Referências}

ALABURDA, J. \& NISHIHARA, L., 1998. Presença de compostos de nitrogênio em águas de poços. $R e$ vista de Saúde Pública, 32:160-165.

BASTOS, R. K. X.; HELLER, L.; FORMAGGIA, D. M. E.; AMORIM, L. C.; SANCHEZ, P. S.; BEVILACQUA, P. D.; COSTA, S. S. \& CANCIO, J. A., 2001. Revisão da Portaria 36 GM/90: Premissas e princípios norteadores. In: 21ㅇ Congresso Brasileiro de Engenharia Sanitária e Ambiental, Anais, pp. 1-12, João Pessoa: Associação Brasileira de Engenharia Sanitária e Ambiental.

BRANCO, S. M., 1991. Aspectos institucionais e legais do controle da poluição. In: Hidrologia Ambiental (R. L. L. Porto, org.), pp. 349-373, São Paulo: Associação Brasileira de Recursos Hídricos/Edusp.

BRASIL, 1986. Resolução CONAMA no 20, de 18 de junho de 1986. Estabelece a classificação das águas doces, salobras e salinas. Diário Oficial [da] República Federativa do Brasil, Brasília, p. 11.356, 30 jul.

BRISCOE, J., 1984. Intervention studies and the definition of dominant transmission routes. American Journal of Epidemiology, 120:449-455.

BRISCOE, J., 1987. Abastecimiento de agua y servicios de saneamiento: Su función en la revolución de la supervivencia infantil. Boletín de la Oficina Sanitaria Panamericana, 103:325-339.

CAIRNCROSS, S., 1984. Aspectos de saúde nos sistemas de saneamento básico. Engenharia Sanitária, 23:334-338.

CAIRNCROSS, S., 1989. Water supply and sanitation: An agenda for research. Journal of Tropical Medicine and Hygiene, 92:301-314.

CAIRNCROSS, S.; BLUMENTHAL, U.; KOLSKY, P.; MORAES, L. \& TAYEH, A., 1996. The public and domestic domains in the transmission disease. Tropical Medicine and International Health, 1:27-34.

CAIRNCROSS, S. \& FEACHEM, R. G., 1990. Environmental Health Engineering in the Tropics: An Introductory Text. Chichester: John Wiley \& Sons.
CAIRNCROSS, S. \& KOLSKY, P. J., 1997. Re: Water, waste and well-being: A multicountry study. American Journal of Epidemiology, 146:359-361.

CLARK, R. M. \& COYLE, J. A., 1990. Measuring and modeling variations in distribution system water quality. Journal of the American Water Works Association, 82:46-52.

CORDEIRO, J. S., 2000. Importância do tratamento e disposição adequada dos lodos de ETAs. In: Noções Gerais de Tratamento e Disposição Final de Lodos de Estações de Tratamento de Água (M. A. P. Reali, org.), pp. 1-19, Rio de Janeiro: Associação Brasileira de Engenharia Sanitária e Ambiental.

COSTA, A. M., 1994. Análise Histórica do Saneamento no Brasil. Dissertação de Mestrado, Rio de Janeiro: Escola Nacional de Saúde Pública, Fundação Oswaldo Cruz.

CVJETANOVIC, B., 1986. Health effects and impact of water supply and sanitation. World Health Statistics Quarterly, 39:105-117.

D'AGUILA, P. S.; ROQUE, O. C. C.; MIRANDA, C. A. S. \& FERREIRA, A. P., 2000. Avaliação da qualidade de água para abastecimento público do Município de Nova Iguaçu. Cadernos de Saúde Pública, 16: 791-798.

DANIEL, F. B.; CONDIE, L. W.; ROBINSON, M.; STOBER, J. A.; YORK, R. G.; OLSON, G. R. \&WANG, S. R., 1990. Comparative subchronic toxicity studies of three disinfectants. Journal of the American Water Works Association, 82:61-69.

ESREY, S. A., 1996. Water, waste and well-being: A multicountry study. American Journal of Epidemiology, 143:608-623.

ESREY, S. A.; POTASH, J. B.; ROBERTS, L. \& SHIFF, C., 1991. Effects of improved water supply and sanitation on ascariasis, diarrhoea, dracunculiasis, hookworm infection, schistosomiasis, and trachoma. Bulletin of the World Health Organization, 69:609-621.

FEACHEM, R. G.; BRADLEY, D. J.; GARELICK, H. \& 
MARA, D. D., 1983. Sanitation and Disease: Health Aspects of Excreta and Wastewater Management. Chichester: John Wiley \& Sons.

GEROLOMO, M. \& PENNA, M. L. F., 2000. Cólera e condições de vida da população. Revista de Saúde Pública, 34:342-347.

GOMES, S. L., 1995. Engenharia Ambiental e Saúde Coletiva. Salvador: Editora da Universidade Federal da Bahia.

HELLER, L., 1997. Saneamento e Saúde. Brasília: Organização Pan-Americana da Saúde/Organização Mundial da Saúde.

HUNTER, P. R., 2001. International report: Health related water microbiology. In: 2nd IWA World Water Congress, Proceedings, pp. 1-8. Berlin: International Water Association.

LIJKLEMA, L., 1995. Water quality standards: Sense and nonsense. Water Science \& Technology, 31: 321-327.

MARA, D. D. \& ALABASTER, G. P., 1995. An environmental classification of housing-related diseases in developing countries. Journal of Tropical Medicine and Hygiene, 98:41-51.

MARA, D. D. \& FEACHEM, R. G. A., 1999. Water- and excreta-related diseases: Unitary environmental classification. Journal of Environmental Engineering, 125:334-339.

METCALF \& EDDY INCORPORATION, 1991. Wastewater Engineering: Treatment, Disposal and Reuse. New York: McGraw-Hill.

MORAES, L. R. S.; BORJA, P. C. \& TOSTA, C. S., 1999. Qualidade de água da rede de distribuição e de beber em assentamento periurbano: Estudo de caso. In: 20o Congresso Brasileiro de Engenharia Sanitária e Ambiental, Anais, pp. 1462-1472. Rio de Janeiro: Associação Brasileira de Engenharia Sanitária e Ambiental.

MS (Ministério da Saúde), 1990. Portaria no 36, de 19 de janeiro de 1990. Aprova normas e o padrão de potabilidade da água para o consumo humano em todo o território nacional. Diário Oficial [da] República Federativa de Brasil, Brasília, p. 16511654, 23 jan. Seção 1.

MS (Ministério da Saúde), 2000. Portaria no 1469, de 29 de dezembro de 2000. Estabelece os procedimentos e responsabilidade relativos ao controle e vigilância da qualidade da água para consumo humano e seu padrão de potabilidade, e dá outras providências. Diário Oficial [da] República Federativa de Brasil, Brasília, 22 fev. Seção 1.
NASCIMENTO, L. V. \& von SPERLING, M., 1998. Os padrões brasileiros de qualidade das águas e os critérios para proteção da vida aquática, saúde humana e animal. In: XXVI Congresso Interamericano de Engenharia Sanitária e Ambiental, Anais, pp. 1-11. Lima: Asociación Interamericana de Ingeniería Sanitaria y Ambiental.

PIMENTEL, C. E. B. \& CORDEIRO NETTO, O. M., 1998. Proposta Metodológica de Classificação e Avaliação Ambiental de Projetos de Saneamento. Brasília: Instituto de Pesquisa Econômica Aplicada.

SHUVAL, H. I.; TILDEN, R. L.; PERRY, B. H. \& GROSSE, R. N., 1981. Effect of investments in water supply and sanitation on health status: A threshold-saturation theory. Bulletin of the World Health Organization, 59:243-248.

TCHOBANOGLOUS, G. \& SCHROEDER, E. D., 1985. Water Quality: Characteristics, Modeling and Modification. New York: Addison-Wesley Publishing Company.

TOMINAGA, M. Y. \& MIDIO, A., 1999. Exposição humana a trialometanos presentes em água tratada. $R e-$ vista de Saúde Pública, 33:413-421.

VANDERSLICE, J. \& BRISCOE, J., 1993. All coliforms are not created equal: A comparison of the effects of water source and in-house water contamination on infantile diarrheal disease. Water Resources Research, 29:1983-1995.

VANDERSLICE, J. \& BRISCOE, J., 1995. Environmental interventions in developing countries: Interactions and their implications. American Journal of Epidemiology, 141:135-144.

von SPERLING, M. \& CHERNICHARO, C. A. L., 2000. A comparison between wastewater treatment processes in terms of compliance with effluent quality standards. In: XXVII Congresso Interamericano de Engenharia Sanitária e Ambiental, Anais, pp. 1-12. Porto Alegre: Asociación Interamericana de Ingeniería Sanitaria y Ambiental.

WHITE, G. F.; BRADLEY, D. J. \& WHITE, A. U., 1972. Drawers of Water: Domestic Water Use in East Africa. Chicago: Chicago University Press.

Recebido em 11 de janeiro de 2002 Aprovado em 11 de abril de 2002 